\title{
BMJ Open Factors associated with mortality among moderate and severe patients with COVID-19 in India: a secondary analysis of a randomised controlled trial
}

Joy John Mammen (D , , Snehil Kumar, ${ }^{1}$ Lovely Thomas, ${ }^{2}$ Gunjan Kumar, ${ }^{3}$ Anand Zachariah, ${ }^{4}$ Lakshmanan Jeyaseelan (D) , ${ }^{5}$ John Victor Peter, ${ }^{2}$ Anup Agarwal, ${ }^{3}$ Aparna Mukherjee, ${ }^{3}$ Pranab Chatterjee, ${ }^{6}$ Tarun Bhatnagar (D) , 7 Jess Elizabeth Rasalam, ${ }^{1}$ Binila Chacko, ${ }^{2}$ Thenmozhi Mani (i) ${ }^{5}$ Melvin Joy (i) , Priscilla Rupali, ${ }^{8}$ Malathi Murugesan, ${ }^{9}$ Dolly Daniel, ${ }^{1}$ B Latha, ${ }^{10}$ Sunita Bundas, ${ }^{11}$ Vivek Kumar, ${ }^{12}$ Ravi Dosi, ${ }^{13}$ Janakkumar R Khambholja, ${ }^{14}$ Rosemarie de Souza, ${ }^{15}$ B Thrilok Chander (D) , ${ }^{16}$ Shalini Bahadur, ${ }^{17}$ Simmi Dube, ${ }^{18}$ Amit Suri, ${ }^{19}$ Aikaj Jindal, ${ }^{20} \mathrm{Om}$ Shrivastav, ${ }^{21}$ Vijay Barge, ${ }^{22}$ Archana Bajpayee, ${ }^{23}$ Pankaj Malhotra, ${ }^{24}$ Neha Singh, ${ }^{25}$ Muralidhar Tambe, ${ }^{26}$ Nimisha Sharma, ${ }^{27}$ Shreepad Bhat, ${ }^{28}$ Ram S Kaulgud, ${ }^{29}$ Anil Gurtoo, ${ }^{30}$ D Himanshu Reddy, ${ }^{31}$ Kamlesh Upadhyay, ${ }^{32}$ Ashish Jain, ${ }^{33}$ Tinkal C Patel, ${ }^{34}$ Irfan Nagori, ${ }^{35}$ Pramod R Jha, ${ }^{36} \mathrm{~K}$ V Sreedhar Babu, ${ }^{37} \mathrm{C}$ Aparna, ${ }^{38}$ Sunil Jodharam Panjwani (D) , ${ }^{39}$ M Natarajan, ${ }^{40}$ Milind Baldi, ${ }^{41}$ Vrushali Khirid Khadke, ${ }^{42}$ Seema Dua, ${ }^{43}$ Ravindraa Singh, ${ }^{44}$ Ashish Sharma, ${ }^{45}$ Jayashree Sharma, ${ }^{46}$ Yojana A Gokhale, ${ }^{47}$ Pragya D Yadav (D) , ${ }^{48}$ Gajanan Sapkal, ${ }^{49}$ Himanshu Kaushal, ${ }^{50}$ V Saravana Kumar ${ }^{51}$

To cite: Mammen JJ, Kumar S, Thomas L, et al. Factors associated with mortality among moderate and severe patients with COVID-19 in India: a secondary analysis of a randomised controlled trial. BMJ Open 2021;11:e050571. doi:10.1136/ bmjopen-2021-050571

- Prepublication history and additional supplemental material for this paper are available online. To view these files, please visit the journal online (http://dx.doi.org/10.1136/ bmjopen-2021-050571).

Received 23 February 2021 Accepted 08 September 2021

Check for updates

(C) Author(s) (or their employer(s)) 2021. Re-use permitted under CC BY-NC. No commercial re-use. See rights and permissions. Published by BMJ.

For numbered affiliations see end of article.

Correspondence to

Dr Joy John Mammen;

joymammen@cmcvellore.ac.in

\section{ABSTRACT}

Objective Large data on the clinical characteristics and outcome of COVID-19 in the Indian population are scarce. We analysed the factors associated with mortality in a cohort of moderately and severely ill patients with COVID-19 enrolled in a randomised trial on convalescent plasma.

Design Secondary analysis of data from a Phase II, Open Label, Randomized Controlled Trial to Assess the Safety and Efficacy of Convalescent Plasma to Limit COVID-19 Associated Complications in Moderate Disease.

Setting 39 public and private hospitals across India during the study period from 22 April to 14 July 2020. Participants of the 464 patients recruited, two were lost to follow-up, nine withdrew consent and two patients did not receive the intervention after randomisation. The cohort of 451 participants with known outcome at 28 days was analysed.

Primary outcome measure Factors associated with allcause mortality at 28 days after enrolment.

Results The mean (SD) age was $51 \pm 12.4$ years; $76.7 \%$ were males. Admission Sequential Organ Failure Assessment score was $2.4 \pm 1$.1. Non-invasive ventilation, invasive ventilation and vasopressor therapy were required in $98.9 \%, 8.4 \%$ and $4.0 \%$, respectively. The 28 -day mortality was $14.4 \%$. Median time from symptom onset to hospital admission was similar in survivors (4 days; IQR 3-7) and non-survivors (4 days; IQR $3-6)$. Patients with two or more comorbidities had $2.25(95 \%$ $\mathrm{Cl} 1.18$ to $4.29, \mathrm{p}=0.014$ ) times risk of death. When compared with survivors, admission interleukin-6 levels were higher

\section{STRENGTHS AND LIMITATIONS OF THIS STUDY}

$\Rightarrow$ There is no study from India with representation from multiple states that has detailed the clinical profile and evaluated for factors associated with death. This study may help with strategic planning at a national level.

$\Rightarrow$ The primary outcome of the Phase II, Open Label, Randomized Controlled Trial to Assess the Safety and Efficacy of Convalescent Plasma to Limit COVID-19 Associated Complications in Moderate Disease, disease progression or all-cause mortality at day 28 did not differ across the trial arms; therefore, the present analysis need not be adjusted for convalescent plasma intervention.

$\Rightarrow$ There may be variability of treatment provided in the multiple centres; however, care was taken that patients received best standard of care for COVID-19 dictated by the best available evidence at the time and guidelines for the management of COVID-19 issued by health authorities of the Indian government.

$\Rightarrow$ The laboratory and biomarker assays for ferritin, lactate dehydrogenase, C-reactive protein and D-dimer were conducted using tests from different manufacturers.

$\Rightarrow$ Participants of this study may not comprise a true observational cohort as this was a post hoc analysis of randomised controlled trial data. Our study did not analyse the effect of SARS-CoV-2 variants causing a high mortality in younger population during the second wave of COVID-19 infection, and therefore extrapolation to the general population must be carefully qualified. 
$(p<0.001)$ in non-survivors and increased further on day 3. On multivariable Fine and Gray model, severity of illness (subdistribution HR 1.22, 95\% Cl 1.11 to 1.35, $\mathrm{p}<0.001), \mathrm{PaO}_{2} / \mathrm{FiO}_{2}$ ratio $<100(3.47,1.64-7.37, \mathrm{p}=0.001)$, neutrophil lymphocyte ratio $>10(9.97,3.65-27.13, p<0.001)$, D-dimer $>1.0 \mathrm{mg} / \mathrm{L}(2.50$, $1.14-5.48, p=0.022)$, ferritin $\geq 500 \mathrm{ng} / \mathrm{mL}(2.67,1.44-4.96, p=0.002)$ and lactate dehydrogenase $\geq 450 \mathrm{IU} / \mathrm{L}(2.96,1.60-5.45, \mathrm{p}=0.001)$ were significantly associated with death.

Conclusion In this cohort of moderately and severely ill patients with COVID-19, severity of illness, underlying comorbidities and elevated levels of inflammatory markers were significantly associated with death. Trial registration number CTRI/2020/04/024775.

\section{INTRODUCTION}

The first human case of COVID-19 caused by the novel coronavirus (named SARS-CoV-2) was reported in Wuhan City, China, in December 2019. On 30 January 2020, the WHO declared that the outbreak of COVID-19 constituted a Public Health Emergency of International Concern. ${ }^{1}$ Based on the high level of global spread and the severity of COVID-19, on 11 March 2020, the DirectorGeneral of the WHO declared the COVID-19 outbreak a pandemic. ${ }^{2}$ The sudden outbreak followed by rapid spread in a globalised world resulted in a huge burden on the healthcare system, besides affecting the socioeconomic well-being among all nations.

In India, the disease was first detected on 30 January 2020 in the state of Kerala, in a student who returned from Wuhan. ${ }^{34}$ After a brief, initial respite, the virus spread at a rapid pace in India, resulting in more than 10 million confirmed cases as of December 2020 with more than 145000 deaths. ${ }^{5}$

Most patients diagnosed with COVID-19 experience mild to moderate respiratory illness, fever, dry cough and fatigue and recover without requiring special treatment. ${ }^{6}$ Oxygen desaturation is the hallmark of progression. Patients with underlying medical problems like cardiovascular disease, diabetes, chronic respiratory disease and cancer are more likely to develop serious illness. These patients may develop viral pneumonia, with resultant dyspnoea and hypoxaemia which may progress to respiratory or multisystem failure and even death. ${ }^{7}$ There is paucity of large-scale data on the clinical characteristics, outcomes of COVID-19 in the Indian population and evaluation of risk factors with an unfavourable outcome at a national level. Identification of such potential risk factors is important to anticipate medical treatment and to reduce the mortality burden for severe COVID-19 illness by proactive interventions.

The Indian Council of Medical Research (ICMR) conducted a randomised trial (a Phase II, Open Label, Randomized Controlled Trial to Assess the Safety and Efficacy of Convalescent Plasma to Limit COVID-19 Associated Complications in Moderate Disease (PLACID Trial)) to determine the effectiveness and safety of convalescent plasma in moderately and severely ill patients with COVID-19 to limit progression of disease. ${ }^{8}$ Patients received standard of care for COVID-19 in keeping with the institutional protocols, based on the best available evidence at the time and guidelines for the management of COVID-19 issued by the national health authorities. Participants in the intervention arm received two doses of $200 \mathrm{~mL}$ of convalescent plasma, transfused 24 hours apart, in addition to standard of care. The control arm did not receive any additional therapy. The study concluded that the use of convalescent plasma was not associated with a reduction in 28-day mortality. ${ }^{8}$

The aim of this analysis was to identify the risk factors associated with mortality by mining the data collected from the cohort enrolled in the PLACID Trial. ${ }^{8}$

\section{METHODS}

\section{Participants}

The study enrolled patients from 39 different hospitals, of which 29 were teaching in public hospitals and 10 were in private facilities across 14 states and union territories. Patients over the age of 18 years who were confirmed to have COVID-19 based on a positive SARS-CoV-2 RT-PCR test and presenting with moderate and severe illness with either a partial pressure of oxygen in arterial blood/ fraction of inspired oxygen $\left(\mathrm{PaO}_{2} / \mathrm{FiO}_{2}\right)$ ratio between 200 and 300 or respiratory rate $>24 / \mathrm{min}$ and decreased oxygen saturation on room air $\left(\mathrm{SpO}_{2}<93 \%\right)$ were included during the study period from 22 April to 14 July 2020. As per the guidelines issued by the Ministry of Health, Government of India at the time of conduct of the study, the subset of patients with the above criteria but with a respiratory rate between 24 and $30 /$ min were classified as moderate disease. Those with respiratory rate $>30$ breaths/min were classified as severe disease. ${ }^{9}$ Patients were followed up for 28 days and assessed for their health status and all-cause mortality. Written consent was obtained from the patients or their families before enrolling in the study.

\section{Data}

Data were obtained from the ICMR PLACID Trial database collected in structured paper case record forms and entered in Research Electronic Data Capture system (version 8.5, Vanderbilt University, Tennessee). The trial protocol was registered with the Clinical Trial Registry of India. After trial completion, based on cooperative agreement between the centres, and Institutional Review Board permission, the data were shared and analysed further to explore for other meaningful results. No separate ethical clearance was taken for this study.

Demographic, clinical, laboratory tests and outcome data were collected prospectively. Clinical symptoms, need for organ support (respiratory, renal, haemodynamic) and laboratory tests (complete blood count, coagulation profile, serum biochemical profile, renal and liver function tests) were monitored serially on day of enrolment (day 0) and on days 1, 3, 5, 7, 14 and 28. Inflammatory biomarkers (lactate dehydrogenase (LDH), serum ferritin and C-reactive protein (CRP)) were tested 
at admission and on days 3 and 7 whereas interleukin- 6 (IL-6) was done at admission and on day 3.

The outcome of interest was all-cause day 28 mortality. In addition, we looked for association between laboratory parameters and mortality.

\section{Statistical methods}

Mean and SD or median and IQR were used for continuous variables as appropriate, and for categorical variables, number and proportions were used. To find the association between mortality and study variables, $\chi^{2}$ test and Fisher's exact test were used. To find the mean difference across the groups, independent t-test was used. Similarly, Mann-Whitney U test was used to compare median difference. The primary endpoint was all-cause mortality (event of interest) at day 28 from the time of enrolment, discharged alive (competing event) or hospital admission after day 28 (censored), whichever was earlier. Discharged alive was treated as a competing event because the event of 'discharged alive' precludes the event of all-cause mortality. The variables that were statistically significant or clinically important were considered in the multivariable Fine and Gray regression model. However, if a variable was expected to have collinear concern or had sparse data, it was not included in the analysis. Two multivariable models were developed. The first model included clinical and laboratory parameters tested on days $0,1,3,5,7,14$ and 28 while the second included inflammatory biomarkers tested on days 0,3 and 7 , after adjusting for age and comorbidities. Variables that were considered included parameters that were strongly associated with mortality at univariate analysis or those known from previous literature to be strongly associated with outcome. For certain laboratory markers such as D-dimer, ferritin and LDH, clinically relevant thresholds were used for the analysis rather than using these data as continuous variables. The clinically relevant thresholds for these variables were set as $>1.0 \mathrm{mg} / \mathrm{L}$ for D-dimer, $\geq 500 \mathrm{mg} / \mathrm{mL}$ for ferritin and $\geq 450 \mathrm{IU} / \mathrm{L}$ for $\mathrm{LDH}$. The threshold for ferritin of $500 \mu \mathrm{g} / \mathrm{L}$ was based on the cut-off value for the diagnosis of haemophagocytic lymphohistiocytosis as well as some preliminary evidence in COVID-19 that a threshold of $>500 \mu \mathrm{g} / \mathrm{L}$ was associated with invasive ventilator dependence. ${ }^{10}$ Similarly, traditionally a threshold of $<0.5 \mathrm{mg} / \mathrm{L}$ is used to exclude pulmonary thromboembolism; in this context two thresholds were used, $0.5-1.0 \mathrm{mg} / \mathrm{L}$ and $>1.0 \mathrm{mg} / \mathrm{L} .{ }^{11}$ The model assumption was verified using $\log -\log S(t)$ plots and global test. A $p$ value $<0.05$ levels was considered as statistically significant. All statistical analyses were performed using STATA V.16.0 (StataCorp. 2019. College Station, Texas).

\section{Patient and public involvement}

Patients and the public were not involved in the design, conduct, reporting or dissemination plans of our research. The study results will be disseminated to the study participants via their treating doctors.

\section{RESULTS}

The PLACID Trial recruited 464 eligible patients for the study. The primary outcome at 28 days was not available for two patients who were lost to follow-up after discharge; nine patients withdrew consent after randomisation and two patients did not receive the intervention after randomisation as a matched donor was not available. The cohort with a known outcome at 28 days thus comprised 451 patients (online supplemental file 1 ).

The primary outcome of the PLACID Trial, disease progression or all-cause mortality at day 28 did not differ across the trial arms, therefore the analysis did not adjust for convalescent plasma intervention. The distribution of patients in the intervention and control arms was 50.3\% $(\mathrm{n}=227)$ and $49.7 \%(\mathrm{n}=224)$, respectively. The mean (SD) age of the cohort was $51 \pm 12.4$ years; $76.7 \%$ were males. Table 1 shows the distribution of demographic variables and clinical parameters in the study population.

The most common presenting symptoms were shortness of breath (91.6\%), fatigue $(78.7 \%)$, cough $(68.5 \%)$ and fever (35\%). Comorbidities were present in $59.9 \%$ of patients; $31.7 \%$ had any one comorbidity and $28.2 \%$ had two or more comorbidities. The most frequent comorbidities were diabetes (43.5\%), hypertension $(37.5 \%)$, obesity $(6.9 \%)$ and chronic obstructive pulmonary disease (COPD) $(3.3 \%)$. There was a history of smoking in $8.2 \%$. The time from onset of symptoms to admission was 4 days (IQR 3-7 days). Majority of the patients required noninvasive $(98.9 \%)$ ventilatory support. The median duration of respiratory support was 6 days (IQR 4-10 days). In this cohort, $4 \%$ of patients required vasopressor support. None of the patients required extracorporeal membrane oxygenation or dialysis support.

The all-cause mortality at 28 days was $14.4 \%$ (95\% CI $11.5 \%$ to $17.9 \%, \mathrm{n}=65)$. Median time from symptom onset to hospital admission was 4 days in survivors (IQR 3-7 days) and non-survivors (IQR 3-6 days). The frequency of shortness of breath, cough and fatigue were similar in survivors and non-survivors; however, the presence of fever at admission was significantly $(p=0 \cdot 042)$ associated with death (table 1). Other than COPD and chronic kidney disease (CKD), other comorbidities were not significantly associated with death (table 1). Admission Sequential Organ Failure Assessment (SOFA) score was higher in non-survivors. The need for invasive mechanical ventilation, duration of invasive mechanical ventilation and vasopressor therapy were associated with death (table 1).

On univariate analysis (table 2), there was an association between increasing age and mortality. Patients with two or more comorbidities had 2.25 (95\% CI 1.18 to 4.29, $\mathrm{p}=0.014$ ) times increased chance of mortality. There was a strong mortality association for platelet count $<100 \times 10^{9} / \mathrm{L}$ (subdistribution HR (SHR) 6.88, 95\% CI 3.61 to 13.13 , $\mathrm{p}<0.001$ ), neutrophil lymphocyte ratio (NLR) $>10$ (28.84, 11.92-69.76, $\mathrm{p}<0.001), \mathrm{LDH} \geq 450 \mathrm{IU} / \mathrm{L}(4.88,2.72-8.75$, $\mathrm{p}<0.001)$, D-dimer $>1 \mathrm{mg} / \mathrm{L}(3.34,1.55-7.19, \mathrm{p}=0.002)$ and ferritin $\geq 500 \mathrm{ng} / \mathrm{mL}$ (4.11, 2.28-7.41, $\mathrm{p}<0.001)$. 
Table 1 Distribution of demographic variables and clinical parameters in enrolled patients and comparison of survivors and non-survivors in the cohort

\begin{tabular}{|c|c|c|c|c|c|}
\hline \multicolumn{2}{|l|}{ Variables } & $\begin{array}{l}\text { Overall }(n=451) \\
N(\%)\end{array}$ & $\begin{array}{l}\text { Survivor }(n=386) \\
N(\%)\end{array}$ & $\begin{array}{l}\text { Non-survivor }(n=65) \\
N(\%)\end{array}$ & $P$ value \\
\hline \multicolumn{2}{|l|}{ Age $($ mean $\pm S D)$} & $51 \pm 12.4$ & $50 \pm 12.4$ & $56 \pm 11.3$ & $<0.001^{*}$ \\
\hline \multirow[t]{3}{*}{ Age } & $\leq 40$ & $104(23.1)$ & $97(25.1)$ & $7(10.8)$ & \multirow[t]{3}{*}{0.004} \\
\hline & $41-59$ & $225(49.9)$ & $194(50.3)$ & $31(47.7)$ & \\
\hline & $\geq 60$ & $122(27.1)$ & 95 (24.6) & $27(41.5)$ & \\
\hline \multicolumn{2}{|l|}{ Gender: male } & $346(76.7)$ & $294(76.2)$ & $52(80.0)$ & 0.499 \\
\hline \multirow[t]{4}{*}{ Blood group } & A & $104(23.1)$ & $91(23.6)$ & $13(20.0)$ & \multirow[t]{4}{*}{0.518} \\
\hline & B & $164(36.4)$ & $140(36.3)$ & $24(36.9)$ & \\
\hline & $A B$ & $25(5.5)$ & $19(4.9)$ & $6(9.2)$ & \\
\hline & $\mathrm{O}$ & $158(35.0)$ & $136(35.2)$ & $22(33.8)$ & \\
\hline \multicolumn{2}{|c|}{ History of smoking } & $37(8.2)$ & $32(8.3)$ & $5(7.7)$ & 0.866 \\
\hline \multicolumn{6}{|c|}{ Comorbidities and chronic illness } \\
\hline \multicolumn{2}{|l|}{ Diabetes } & $196(43.5)$ & $164(42.5)$ & $32(49.2)$ & 0.310 \\
\hline \multicolumn{2}{|l|}{ Hypertension } & $169(37.5)$ & $139(36.0)$ & $30(46.2)$ & 0.118 \\
\hline \multicolumn{2}{|c|}{ Chronic obstructive pulmonary disease } & $15(3.3)$ & $10(2.6)$ & $5(7.7)$ & 0.050 \\
\hline \multicolumn{2}{|l|}{ Obesity $\geq 30$} & $31(6.9)$ & $25(6.5)$ & $6(9.2)$ & 0.426 \\
\hline \multicolumn{2}{|c|}{ Chronic kidney disease } & $17(3.8)$ & $11(2.8)$ & $6(9.2)$ & 0.024 \\
\hline \multicolumn{2}{|c|}{ Coronary artery disease } & $31(6.9)$ & $23(6.0)$ & $8(12.3)$ & 0.106 \\
\hline \multicolumn{2}{|c|}{ Cerebrovascular disease } & $4(0.9)$ & $3(0.8)$ & $1(1.5)$ & 0.465 \\
\hline \multicolumn{6}{|c|}{ Symptoms at admission } \\
\hline \multicolumn{2}{|c|}{ Shortness of breath } & $413(91.6)$ & $351(90.9)$ & $62(95.4)$ & 0.232 \\
\hline \multicolumn{2}{|l|}{ Fever } & $158(35.0)$ & $128(33.2)$ & 30 (46.2) & 0.042 \\
\hline \multicolumn{2}{|l|}{ Cough } & $309(68.5)$ & $259(67.1)$ & $50(76.9)$ & 0.115 \\
\hline \multicolumn{2}{|l|}{ Fatigue } & $354(78.7)$ & $301(78.2)$ & $53(81.5)$ & 0.541 \\
\hline \multicolumn{6}{|c|}{ Severity of illness score } \\
\hline \multicolumn{2}{|c|}{ SOFA score at admission* } & $2.40 \pm 1.06$ & $2.30 \pm 0.93$ & $3.05 \pm 1.49$ & $<0.001$ \\
\hline \multicolumn{6}{|l|}{ Treatment } \\
\hline \multicolumn{2}{|l|}{ Vasopressor } & $18(4.0)$ & $1(0.3)$ & $17(26.6)$ & $<0.001$ \\
\hline \multicolumn{2}{|c|}{ Non-invasive ventilation (NIV) } & 446 (98.9) & $383(99.2)$ & $63(96.9)$ & 0.101 \\
\hline \multicolumn{2}{|c|}{ Invasive ventilation } & $38(8.4)$ & $4(1.04)$ & $34(52.31)$ & $<0.001$ \\
\hline \multicolumn{2}{|c|}{ Interval between symptom onset and admission $\uparrow$} & $4(3,7)$ & $4(3,7)$ & $4(3,6)$ & 0.996 \\
\hline \multicolumn{2}{|c|}{ Duration of respiratory support, days $\dagger$} & $6(4,10)$ & $6(4,9.5)$ & $6(3,10)$ & 0.689 \\
\hline Duration of ir & ntilation, days $\dagger$ & $1(1,3)$ & $12(2,14)$ & $1(1,3)$ & 0.020 \\
\hline Duration of $h$ & ay, days $\dagger$ & $14(10,18)$ & $14(11,19)$ & $8(5,14)$ & $<0.001$ \\
\hline
\end{tabular}

$P$ values are highlighted in bold for statistically significant factors.

${ }^{*}$ Mean \pm SD-independent t-test was used.

†Median (IQR) days in days-Mann-Whitney U test was used.

SOFA, Sequential Organ Failure Assessment.

Admission IL-6 levels were significantly $(\mathrm{p}<0.001)$ higher $(76.00,18.27-171.77)$ in non-survivors than in survivors (18.51, 4.26-56.86). By day 3, IL-6 levels dropped to 11.6 (2.64-45.84) in survivors while it nearly doubled in nonsurvivors $(140.35,21.56-427.36)$. CRP did not show any statistical significance $(1.0003,0.999-1.001, \mathrm{p}=0.080)$.

The need for invasive ventilation and vasopressors were associated with death (table 2). Increasing SOFA score was associated with mortality $(1.63,1.54-1.74, \mathrm{p}<0.001)$.
The mean SOFA score at day 0 was 2.30 and 3.05 for survivors and non-survivors, respectively. The difference in the SOFA score progressively increased between the two groups over time (figure 1). Mortality also proportionately increased with lower $\mathrm{PaO}_{2} / \mathrm{FiO}_{2}$ values with SHR of $25.64(14.8-44.41, \mathrm{p}<0.001)$ in the severe group as compared with the mild group.

Two models were run for multivariable Fine and Gray regression model over a period of time (table 3). 
Table 2 Univariate Fine and Gray model for baseline characteristics, laboratory parameters and inflammatory biomarkers

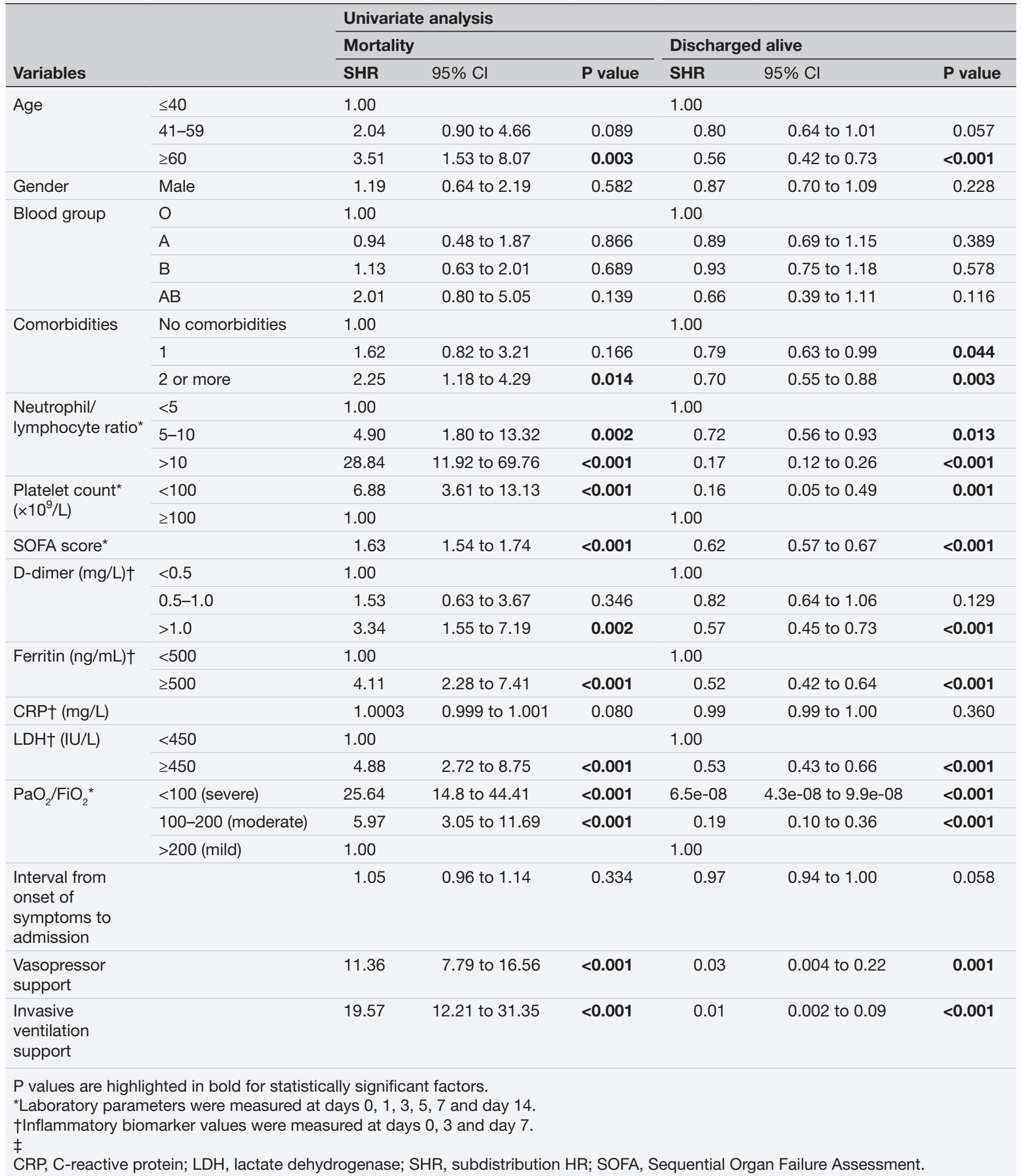

Model A included age, comorbidities, $\mathrm{PaO}_{2} / \mathrm{FiO}_{2}$, NLR and SOFA score. Model A revealed significant SHRs for $\mathrm{PaO}_{9} / \mathrm{FiO}_{9}$ ratio $<100$ (3.47, 1.64-7.37, $\left.\mathrm{p}=0.001\right)$, NLR $>10(9.97,3.65-27.13, \mathrm{p}<0.001)$ and SOFA score $(1.22,1.11-1.35, \mathrm{p}<0.001)$ after adjusting for age and comorbidities. Model B included age, comorbidities, D-dimer, ferritin and LDH. D-dimer $>1 \mathrm{mg} / \mathrm{L}(2.50,1.14$ $5.48, \mathrm{p}=0.022)$, ferritin $\geq 500 \mathrm{ng} / \mathrm{mL}(2.67,1.44-4.96$, $\mathrm{p}=0.002)$ and $\mathrm{LDH} \geq 450 \mathrm{IU} / \mathrm{L}(2.96,1.60-5.45, \mathrm{p}=0.001)$ were associated with mortality after adjusting for age and 


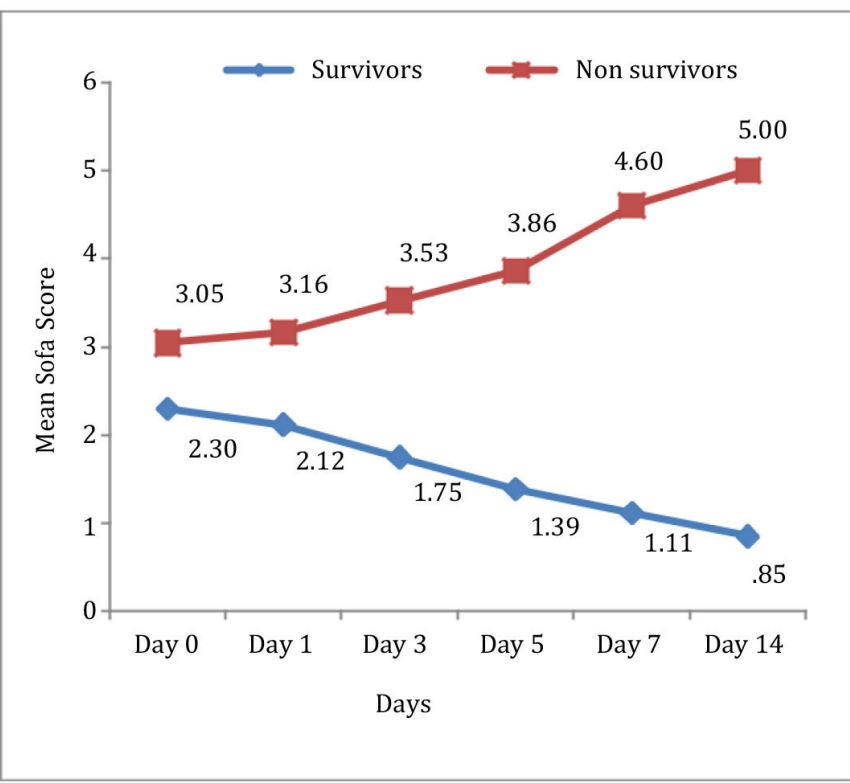

Figure 1 Serial Sequential Organ Failure Assessment (SOFA) score among survivors and non-survivors. Increasing SOFA score was associated with mortality. The mean SOFA score at day 0 was 2.30 and 3.05 for survivors and nonsurvivors, respectively. The difference in the SOFA score showed divergence between the two groups over time.

comorbidities (table 3). IL-6 was omitted from the model as it was not measured on day 7 .

\section{DISCUSSION}

In this study that enrolled patients in the PLACID Trial from across India, SOFA score and clinical biomarkers like D-dimer, LDH and ferritin were identified as factors that could predict increased risk of death in moderately and severely ill patients with COVID-19. The definition of clinical grading of severity is different in India as compared with other countries. ${ }^{12-16}$ Mortality of critically ill patients with COVID-19 varies significantly among already published case series and ranges from $16 \%$ to $78 \% .^{17-23}$ Two studies from Wuhan, which included moderately as well as critically ill patients, showed mortality rates of $3.77 \%$ and $14.14 \% .^{24}{ }^{25}$ This wide variability can be explained by differences in the age of the population, distribution of risk factors, health system responses, varied treatment protocols and disparate follow-up times. In a series of critically ill patients in China, the 28-day intensive care unit mortality was $61.5 \% .^{26}$ In a multicentric study from Italy, the mortality risk for patients without respiratory failure at admission was $1 \%$ after 15 days, while survival in patients with moderate to severe respiratory failure $\left(\mathrm{PaO}_{2} / \mathrm{FiO}_{2} \leq 200 \mathrm{~mm} \mathrm{Hg}\right)$ at admission was only $56 \%$ at 15 days. ${ }^{27}$ The fatality rate reported in Europe and the USA was significantly higher than in China. ${ }^{28}$ Therefore, findings obtained in a specific country might not be automatically extrapolated and national cohorts must be studied.
In our study population, mortality increased with age; this pattern was observed in other countries affected by COVID-19. Age seemed to affect the time from hospitalisation to death. Age-specific death rates were quite similar in studies from Asia, Europe and North America. ${ }^{29}$ In South Korea, Italy, France, Germany, England and Wales and Spain, the COVID-19 attributed mortality rates rose by about $12 \%$ per year whereas the USA and Wuhan, China had a lower rate of increase of about $9.5 \%$ per year of age. ${ }^{30}$ In a meta-analysis of 611583 subjects, the overall mortality was $12.10 \%$; the lowest mortality rate was reported from China (3.1\%) and the highest in the UK $(20.8 \%)$ and New York state (20.99\%). Among the patients included in the meta-analysis, $23.2 \%$ were $\geq 80$ years of age; mortality was highest in these patients. The largest increase in mortality risk was observed in patients aged 60-69 years as compared with those aged 50-59 years (OR 3.13, 95\% CI 2.61 to 3.76$){ }^{31}$

The presence of comorbidities significantly increases the death risk due to COVID-19. A higher risk of mortality was seen in our patients who had CKD and COPD. A meta-analysis, including 1389 patients with COVID-19, with $19.7 \%$ having severe disease showed a significant association of CKD with severe COVID-19 with pooled OR of $3.03 .^{32}$ Similarly, the estimated mortality risk in patients with COPD was three times than those without $(p<0.05){ }^{33}$ We found that $43.5 \%$ of our patients had diabetes which is markedly higher when compared with patients from Korea which showed that $16.97 \%$ had diabetes mellitus. ${ }^{34}$ Our analysis showed that the presence of diabetes was not significantly different between survivors and non-survivors ( $42.5 \%$ vs $49.2 \%, \mathrm{p}=0.310)$, in contrast to the study from South Korea ${ }^{34}$ which showed a much higher mortality among patients with diabetes than in those without $(20.0 \%$ vs $4.8 \%)$. Hypertension and obesity were not significantly different among survivors and non-survivors in our study. However, the presence of two or more comorbidities was associated with mortality in our study.

The Fine-Gray model identified prognostic markers for mortality, most notablyage $\geq 60$ years, $\mathrm{PaO}_{2} / \mathrm{FiO}_{2}$ ratio $<100$, NLR $>10$, platelet count $<100 \times 10^{9} / \mathrm{L}$, ferritin $>500 \mathrm{ng} /$ $\mathrm{mL}, \mathrm{LDH}>450 \mathrm{IU} / \mathrm{L}$ and D-dimer $>1 \mathrm{mg} / \mathrm{L}$. Our study findings were similar when compared with studies from Wuhan. ${ }^{35}$ Older age, leucocytosis and high LDH level have been reported to be risk factors associated with in-hospital death in other studies also. ${ }^{36-38}$ IL-6 levels were significantly different in survivors and non-survivors at admission. By day 3, survivors had reducing IL-6 while it nearly doubled in non-survivors.

Mortality was higher among patients requiring invasive mechanical ventilation (SHR 19.57, 12.21-31.35, $\mathrm{p}<0.001$ ) and those requiring vasopressors (SHR 11.36, $7.79-16.56, \mathrm{p}<0.001)$. However, the median duration of invasive ventilation for survivors was 12 days (IQR 2, 14) and that for non-survivors was 1 day (IQR 1, 3). These results suggest that the sickest patients probably die very early in the course of hospitalisation, while patients with 


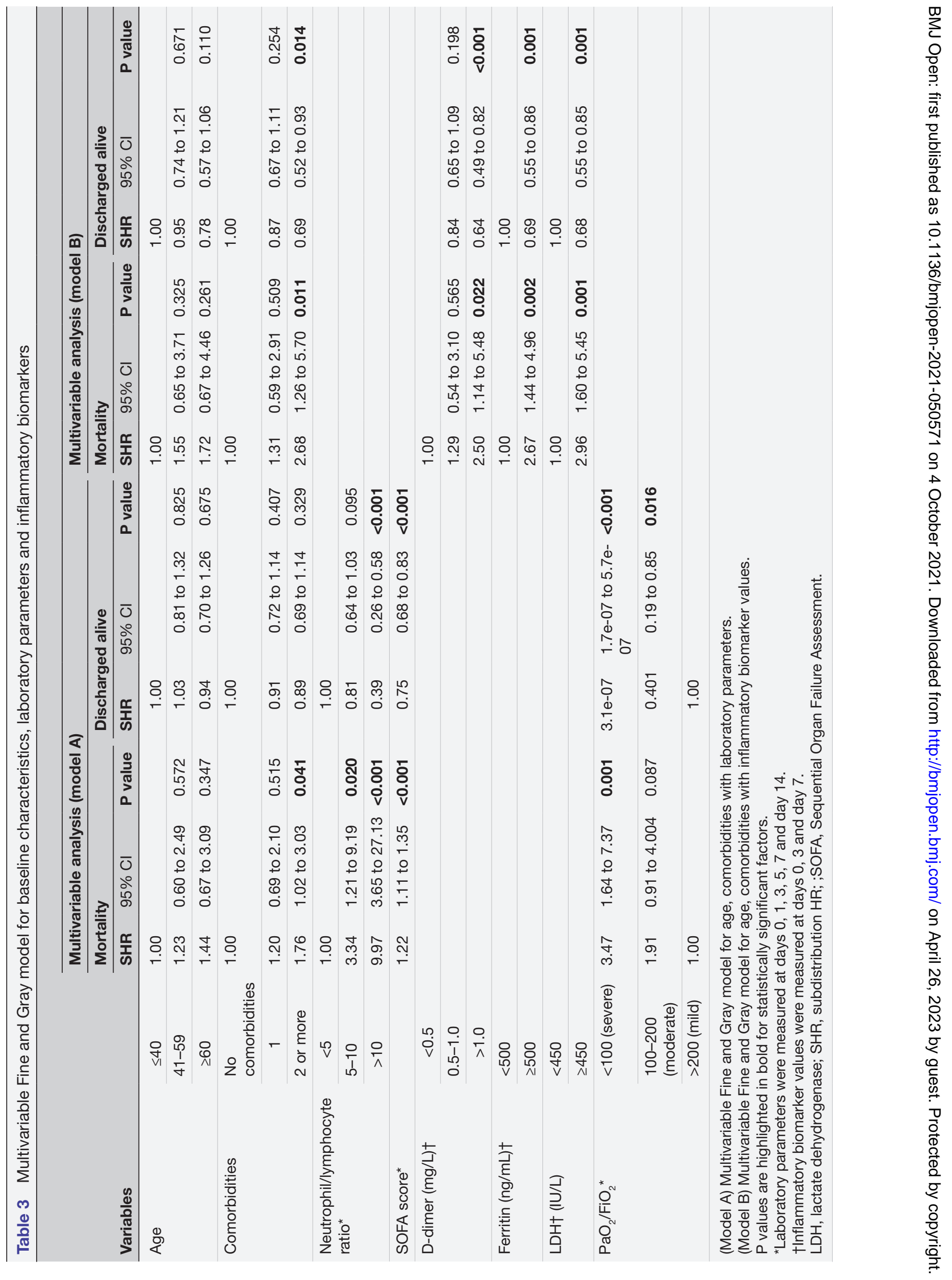


acute respiratory failure requiring ventilatory support may survive with prolonged ventilatory support. Therefore, invasive ventilation should be offered in a timely manner and effectively provided.

In our study, the SOFA score was recognised as a valuable tool that could be used to prognosticate the outcome of patients with COVID-19. Competing risk regression models showed that the increase in SOFA score was related to mortality, with a clearly divergent pattern between the two groups. Thus, an increasing SOFA score over time may be a factor that can be used to identify a subset of patients who may have an unfavourable outcome. Studies have shown that the SOFA score could be used to evaluate severity and 60-day mortality of COVID-19 with the optimal cut-off score of $5 .^{39}$

The limitations of this study include the variability of treatment provided in the multiple centres. The participants of this study may not comprise a true observational cohort, as this was a post hoc analysis of randomised controlled trial data and extrapolation to the general population must be carefully qualified. Our study did not analyse the effect of SARS-CoV-2 variants causing a high mortality in younger population during the second wave of COVID-19 infection and this may limit generalisability of the data to the second wave. Despite these limitations, this study provides a comprehensive overview of prognostic factors in moderately and severely ill patients with COVID-19 that included patients from across the country.

\section{CONCLUSION}

Older age, multiple comorbidities, low $\mathrm{PaO}_{2} / \mathrm{FiO}_{2}$ ratio and elevated levels of inflammatory markers are associated with worse prognosis. Serial SOFA score can be used for prognostication. Understanding the symptoms, burden of comorbidities and systematic monitoring of key laboratory parameters offer opportunities for targeted intervention in COVID-19 with the use of anti-inflammatory or immunomodulatory agents.

\section{Author affiliations}

${ }^{1}$ Transfusion Medicine and Immunohaematology, Christian Medical College and Hospital Vellore, Vellore, Tamil Nadu, India

${ }^{2}$ Medical Intensive Care Unit, Christian Medical College and Hospital Vellore, Vellore, Tamil Nadu, India

${ }^{3}$ Clinical Trials and Health Systems Research Unit, ICMR, New Delhi, Delhi, India ${ }^{4}$ Medicine, Christian Medical College and Hospital Vellore, Vellore, Tamil Nadu, India ${ }^{5}$ Biostatistics, Christian Medical College and Hospital Vellore, Vellore, Tamil Nadu, India

${ }^{6}$ Translational Global Health Policy and Research Cell, ICMR, New Delhi, Delhi, India ${ }^{7}$ ICMR School of Public Health, National Institute of Epidemiology, Chennai, Tamil Nadu, India

${ }^{8}$ Infectious Diseases, Christian Medical College and Hospital Vellore, Vellore, Tamil Nadu, India

${ }^{9}$ Hospital Infection Control Committee, Christian Medical College and Hospital Vellore, Vellore, Tamil Nadu, India

${ }^{10}$ Transfusion Medicine, Madras Medical College, Chennai, Tamil Nadu, India

${ }^{11}$ Transfusion Medicine, SMS Medical College and Hospital, Jaipur, Rajasthan, India

${ }^{12}$ Critical Care, Sir HN Reliance Foundation Hospital and Research Centre, Mumbai,

Maharashtra, India
${ }^{13}$ Respiratory Medicine, Sri Aurobindo Institute of Medical Sciences, Indore, Madhya Pradesh, India

${ }^{14}$ Internal Medicine, Smt NHL Municipal Medical College, Ahmedabad, Gujarat, India

${ }^{15}$ Department of Medicine, BYL Nair Charitable Hospital, Mumbai, India

${ }^{16}$ Internal Medicine, Gandhi Medical College and Hospital, Secunderabad-Padmarao Nagar, Telangana, India

${ }^{17}$ Pathology, Government Institute of Medical Sciences, Noida, Uttar Pradesh, India

${ }^{18}$ Internal Medicine, Gandhi Medical College Bhopal, Bhopal, Madhya Pradesh, India

${ }^{19}$ Pulmonary Medicine, Atal Bihari Vajpayee Institute of Medical Sciences and Ram

Manohar Lohia Hospital, New Delhi, Delhi, India

${ }^{20}$ Transfusion Medicine, Satguru Partap Singh Hospitals, Ludhiana, Punjab, India

${ }^{21}$ Infectious Diseases, Kasturba Hospital for Infectious Diseases, Mumbai,

Maharashtra, India

${ }^{22}$ Medicine, RCSM Government Medical College, Kolhapur, Maharashtra, India

${ }^{23}$ Transfusion Medicine, AllMS Jodhpur, Jodhpur, Rajasthan, India

${ }^{24}$ Department of Internal Medicine, Post Graduate Institute of Medical Education and

Research, Chandigarh, Punjab, India

${ }^{25}$ Transfusion Medicine, AllMS Patna, Patna, Bihar, India

${ }^{26}$ Department of Community Medicine, B J Government Medical College, Pune, India

${ }^{27}$ Transfusion Medicine, ESIC Medical College and Hospital Faridabad, Faridabad, Haryana, India

${ }^{28}$ Internal Medicine, Smt Kashibai Navale Medical College and General Hospital,

Pune, Maharashtra, India

${ }^{29}$ Internal Medicine, Karnataka Institute of Medical Sciences, Hubli, Karnataka, India

${ }^{30}$ Internal Medicine, Lady Hardinge Medical College, New Delhi, Delhi, India

${ }^{31}$ Internal Medicine, King George Medical College, Lucknow, Uttar Pradesh, India

${ }^{32}$ Internal Medicine, Byramjee Jeejeebhoy Medical College, Ahmedabad, Gujarat, India

${ }^{33}$ Respiratory Medicine, Mahatma Gandhi Medical College and Hospital, Jaipur,

Rajasthan, India

${ }^{34}$ Internal Medicine, Government Medical College, Surat, Gujarat, India

${ }^{35}$ Medicine, GMERS Medical College Gotri Vadodara, Vadodara, Gujarat, India

${ }^{36}$ Internal Medicine, Sumandeep Vidyapeeth University, Vadodara, Gujarat, India

${ }^{37}$ Transfusion Medicine, Sri Venkateswara Institute of Medical Sciences, Tirupati, Andhra Pradesh, India

${ }^{38}$ Pathology, Kurnool Medical College, Kurnool, Andhra Pradesh, India

${ }^{39}$ Internal Medicine, Government Medical College, Bhavnagar, Gujarat, India

${ }^{40}$ Internal Medicine, Madurai Medical College, Madurai, Tamil Nadu, India

${ }^{41}$ Internal Medicine, Mahatma Gandhi Memorial Medical College, Indore, UK

${ }^{42}$ Interventional Pulmonology, Poona Hospital and Research Centre, Pune,

Maharashtra, India

${ }^{43}$ Transfusion Medicine, Super Speciality Paediatric Hospital and Teaching Hospital, Noida, Uttar Pradesh, India

${ }^{44}$ Transfusion Medicine, Aditya Birla Memorial Hospital, Pune, Maharashtra, India

${ }^{45}$ Medicine, R D Gardi Medical College, Ujjain, Madhya Pradesh, India

${ }^{46}$ Transfusion Medicine, Seth GS Medical College and KEM Hospital, Mumbai, Maharashtra, India

${ }^{47}$ Internal Medicine, Lokmanya Tilak Municipal Medical College and General Hospital, Mumbai, Maharashtra, India

${ }^{48}$ Maximum Containment Laboratory, ICMR, National Institute of Virology, Pune, Maharashtra, India

${ }^{49}$ Diagnostic Virology Group, ICMR, National Institute of Virology, Pune, Maharashtra, India

${ }^{50}$ Human Influenza Group, ICMR, National Institute of Virology, Pune, Maharashtra, India

${ }^{51}$ Epidemiology and Biostatistics Division, National Institute of Epidemiology, Chennai, Tamil Nadu, India

Twitter Tarun Bhatnagar @tarunb20

Acknowledgements We acknowledge the ICMR for providing us the data collected during PLACID Trial which were analysed in the present study.

Contributors All the authors contributed equally in the study and the specific contributions are mentioned in the manuscript. Study design: JJM, LJ, JVP. Clinical management: SK, LT, AZ, JER, BC, BL, SBu, VK, RD, JRK, RdS, BTC, SBa, SDub, ASu, AJi, OS, VB, AB, PM, NSi, MT, NSh, SBh, RSK, AG, DHR, KU, AJa, TCP, IN, PRJ, KVSB, CA, SJP, MN, MB, VKK, SDua, RS, AS, JS, YAG. Data collection: JJM, SK, LT, AZ, AA, AM, GK, PC, TB, JER, PR, MM, BC, BL, SBu, VK, RD, JRK, RdS, BTC, SBa, SDub, ASu, AJi, OS, VB, AB, PM, NSi, MT, NSh, SBh, RSK, AG, DHR, KU, AJa, TCP, IN, PRJ, KVSB, CA, SJP, MN, MB, VKK, SDua, RS, ASh, JS, YAG, PDY, GS, HK, VSK. Data analysis: 
JJM, SK, LJ, TM, MJ, PR, MM, DD, JVP. Data interpretation: JJM, SK, AZ, LJ, JER, TM, MJ, DD, JVP. Manuscript writing: JJM, SK, LT, AZ, LJ, JER, BC, TM, MJ, PR, MM, DD, JVP, AA, AM, GK, HK, PC, TB. Study administration: JJM, BC, JVP, AA, AM, GK, HK, PC, TB.

Funding The funding source for the primary study was ICMR (RFC No ECD/ NTF/20/2020-21/Covid, 23 July 2020).

Competing interests None declared.

Patient consent for publication Not applicable.

Ethics approval Ethical approval was obtained from the ICMR Central Ethics Committee on Human Research (CECHR-002/2020) based in the National Center for Disease Informatics and Research, Indian Council of Medical Research, Bengaluru, Karnataka, as well as from the Institutional Review Boards (IRB)/Institutional Ethics Committees of all the participating hospitals.

Provenance and peer review Not commissioned; externally peer reviewed.

Data availability statement Data are available upon reasonable request. Data will be made available, upon request, and must be accompanied by a brief proposal outlining the analysis plan. A signed data access agreement might be needed to ensure data safety and compliance with national rules about data sharing.

Supplemental material This content has been supplied by the author(s). It has not been vetted by BMJ Publishing Group Limited (BMJ) and may not have been peer-reviewed. Any opinions or recommendations discussed are solely those of the author(s) and are not endorsed by BMJ. BMJ disclaims all liability and responsibility arising from any reliance placed on the content. Where the content includes any translated material, BMJ does not warrant the accuracy and reliability of the translations (including but not limited to local regulations, clinical guidelines, terminology, drug names and drug dosages), and is not responsible for any error and/or omissions arising from translation and adaptation or otherwise.

Open access This is an open access article distributed in accordance with the Creative Commons Attribution Non Commercial (CC BY-NC 4.0) license, which permits others to distribute, remix, adapt, build upon this work non-commercially, and license their derivative works on different terms, provided the original work is properly cited, appropriate credit is given, any changes made indicated, and the use is non-commercial. See: http://creativecommons.org/licenses/by-nc/4.0/.

\section{ORCID iDs}

Joy John Mammen http://orcid.org/0000-0003-4402-7371

Lakshmanan Jeyaseelan http://orcid.org/0000-0002-9090-3005

Tarun Bhatnagar http://orcid.org/0000-0002-5603-1418

Thenmozhi Mani http://orcid.org/0000-0002-3932-5625

Melvin Joy http://orcid.org/0000-0001-9323-994X

B Thrilok Chander http://orcid.org/0000-0002-6151-3868

Sunil Jodharam Panjwani http://orcid.org/0000-0003-2267-2804

Pragya D Yadav http://orcid.org/0000-0002-0861-7166

\section{REFERENCES}

1 Mullen L, Potter C, Gostin LO, et al. An analysis of international health regulations emergency committees and public health emergency of international concern designations. BMJ Glob Health 2020;5:e002502.

2 Cucinotta D, Vanelli M. WHO declares COVID-19 a pandemic. Acta Biomed 2020;91:157-60.

3 Perappadan BS. India's first coronavirus infection confirmed in Kerala. The Hindu [online], 2020. Available: https://www.thehindu. $\mathrm{com} /$ news/national/indias-first-coronavirus-infection-confirmed-inkerala/article30691004.ece [Accessed 17 Nov 2020].

4 Andrews MA, Areekal B, Rajesh KR, et al. First confirmed case of COVID-19 infection in India: a case report. Indian J Med Res 2020;151:490.

5 MoHFW | Home [online]. Available: https://www.mohfw.gov.in/ [Accessed 3 Jan 2021].

6 Yuki K, Fujiogi M, Koutsogiannaki S. COVID-19 pathophysiology: a review. Clinical Immunology 2020;215:108427.

7 Wu C, Chen X, Cai Y, et al. Risk factors associated with acute respiratory distress syndrome and death in patients with coronavirus disease 2019 pneumonia in Wuhan, China. JAMA Intern Med 2020;180:934-43.

8 Agarwal A, Mukherjee A, Kumar G. Convalescent plasma in the management of moderate covid-19 in adults in India: open label phase II multicentre randomised controlled trial (PLACID trial). BMJ 2020;151:m3939.
9 Government of India, Ministry of Health and Family Welfare, Directorate General of Health Services. Clinical management protocol for COVID-19-Version 3. Government of India 2020.

10 Qeadan F, Tingey B, Gu LY, et al. Prognostic values of serum ferritin and D-dimer trajectory in patients with COVID-19. Viruses 2021;13:1. doi:10.3390/v13030419

11 Kearon C, de Wit K, Parpia S, et al. Diagnosis of pulmonary embolism with D-dimer adjusted to clinical probability. N Engl J Med 2019;381:2125-34

12 Varghese GM, John R, Manesh A, et al. Clinical management of COVID-19. Indian J Med Res 2020;151:401.

13 Clinical management of COVID-19 [online]. Available: https:// www.who.int/publications/i/item/clinical-management-of-covid-19 [Accessed 3 Jan 2021].

14 Zhang S-Y, Lian J-S, Hu J-H, et al. Clinical characteristics of different subtypes and risk factors for the severity of illness in patients with COVID-19 in Zhejiang, China. Infect Dis Poverty 2020;9:85.

15 Xia L, Chen J, Friedemann T, et al. The course of mild and moderate COVID-19 infections - the unexpected long-lasting challenge. Open Forum Infect Dis 2020;7.

16 Verity R, Okell LC, Dorigatti I, et al. Estimates of the severity of coronavirus disease 2019: a model-based analysis. Lancet Infect Dis 2020;20:669-77.

17 Grasselli G, Greco M, Zanella A, et al. Risk factors associated with mortality among patients with COVID-19 in intensive care units in Lombardy, Italy. JAMA Intern Med 2020;180:1345-55.

18 Huang C, Wang Y, Li X, et al. Clinical features of patients infected with 2019 novel coronavirus in Wuhan, China. Lancet 2020;395:497-506.

19 Wang Y, Lu X, Li Y, et al. Clinical course and outcomes of 344 intensive care patients with COVID-19. Am J Respir Crit Care Med 2020;201:1430-4.

20 Wang D, Hu B, Hu C, et al. Clinical characteristics of 138 hospitalized patients with 2019 novel coronavirus-infected pneumonia in Wuhan, China. JAMA 2020;323:1061-9.

21 Bhatraju PK, Ghassemieh BJ, Nichols M, et al. Covid-19 in critically III patients in the seattle region - case series. $N$ Engl J Med 2020;382:2012-22.

22 Arentz M, Yim E, Klaff L, et al. Characteristics and outcomes of 21 critically ill patients with COVID-19 in Washington state. JAMA 2020;323:1612-4.

23 Zhou F, Yu T, Du R, et al. Clinical course and risk factors for mortality of adult inpatients with COVID-19 in Wuhan, China: a retrospective cohort study. Lancet 2020;395:1054-62.

24 Zhang J, Wang X, Jia X, et al. Risk factors for disease severity, unimprovement, and mortality in COVID-19 patients in Wuhan, China. Clin Microbiol Infect 2020;26:767-72.

25 Chen T, Wu D, Chen H, et al. Clinical characteristics of 113 deceased patients with coronavirus disease 2019: retrospective study. BMJ 2020;368:m1091.

26 Yang $\mathrm{X}, \mathrm{Yu} \mathrm{Y}, \mathrm{Xu} \mathrm{J}$, et al. Clinical course and outcomes of critically ill patients with SARS-CoV-2 pneumonia in Wuhan, China: a singlecentered, retrospective, observational study. Lancet Respir Med 2020;8:475-81

27 Santus P, Radovanovic D, Saderi L, et al. Severity of respiratory failure at admission and in-hospital mortality in patients with COVID-19: a prospective observational multicentre study. BMJ Open 2020;10:e043651.

28 Yamamoto N, Bauer G. Apparent difference in fatalities between central Europe and East Asia due to SARS-COV-2 and COVID-19: four hypotheses for possible explanation. Med Hypotheses 2020;144:110160.

29 Ined - Institut national d'études démographiques. Demographics of COVID-19 Deaths [online]. Available: https://dc-covid.site.ined.fr/en/ [Accessed 16 Nov 2020].

30 Goldstein JR, Lee RD. Demographic perspectives on the mortality of COVID-19 and other epidemics. Proc Natl Acad Sci U S A 2020;117:22035-41.

31 Bonanad C, García-Blas S, Tarazona-Santabalbina F, et al. The effect of age on mortality in patients with COVID-19: a meta-analysis with 611,583 subjects. J Am Med Dir Assoc 2020;21:915-8.

32 Henry BM, Lippi G. Chronic kidney disease is associated with severe coronavirus disease 2019 (COVID-19) infection. Int Urol Nephrol 2020:1-2

33 Venkata VS, Kiernan G. COVID-19 and COPD: pooled analysis of observational studies. Chest 2020;158:A2469.

34 Acharya D, Lee K, Lee YS. Mortality rate and predictors of mortality in hospitalized COVID-19 patients with diabetes. Healthc Basel Switz 2020;8. 
35 Du R-H, Liang L-R, Yang C-Q. Predictors of mortality for patients with COVID-19 pneumonia caused by SARS-CoV-2: a prospective cohort study. Eur Respir J 2020;55

36 Li M, Cheng B, Zeng W, et al. Analysis of the risk factors for mortality in adult COVID-19 patients in Wuhan: a multicenter study. Front Med 2020;7

37 Albitar O, Ballouze R, Ooi JP, et al. Risk factors for mortality among COVID-19 patients. Diabetes Res Clin Pract 2020;166:108293.
38 Holman N, Knighton P, Kar P, et al. Risk factors for COVID-19-related mortality in people with type 1 and type 2 diabetes in England: a population-based cohort study. Lancet Diabetes Endocrinol 2020;8:823-33.

39 Yang Z, Hu Q, Huang F. The prognostic value of the SOFA score in patients with COVID-19: a retrospective observational study 2020 https://europepmc.org/article/ppr/ppr231113 